\title{
A JURISDiÇÃo CONSTITUCiONAL BRASILEIRA EM MATÉRIA de TraTAdOS INTERNACIONAIS SOB A PERSPECTIVA DO ESTADO CONSTITUCIONAL COOPERATIVO
}

\author{
BRAZILIAN CONSTITUTIONAL LAW WITH REGARD TO INTERNATIONAL TREATIES FROM \\ the Perspective of The CoOperative Constitutional State
}

Ricardo Victalino de Oliveira ${ }^{1}$

\begin{abstract}
Resumo
Constituem objetivo central deste trabalho a análise e o mapeamento das influências determinadas pela teoria do Estado Constitucional Cooperativo, idealizada por Peter Häberle, no campo do controle de constitucionalidade de tratados internacionais incorporados ao ordenamento jurídico pátrio. É apresentada, portanto, a proposta de verificar a intensidade e as formas com que o pensamento de Häberle - que apregoa, em síntese, a necessidade de ampla aproximação entre o Direito Constitucional e o Direito Internacional - repercute na operacionalização de nosso complexo sistema de jurisdição constitucional, abordando-se, com destaque, as implicações que decorrem da apreciação da compatibilidade dos tratados internacionais em relação à Constituição. Em última análise, busca-se aqui empreender um estudo acerca da evolução jurisprudencial processada no âmbito de nossos tribunais superiores a respeito do enquadramento hierárquico-normativo conferido aos atos normativos convencionais, cuja gênese reside no campo do Direito Internacional Público.
\end{abstract}

Palavras-chaves: Controle de constitucionalidade. Tratados internacionais. Estado Constitucional Cooperativo. Hierarquia de tratados.

\section{INTRODUÇÃO}

A emergência de um cenário internacional marcado pela progressiva inserção dos Estados no plano das negociações internacionais e pelo consequente abandono do paradigma que considerava o Direito Internacional como sendo unicamente um direito de coexistência pacífica entre Estados (isto é, de delimitação dos âmbitos da soberania nacional) determinam hoje a verificação de múltiplos impactos na organização constitucional dos Estados ${ }^{2}$. Tal

1 Doutorando e mestre em Direito do Estado - área de concentração: Direito Constitucional - pela Universidade de São Paulo (USP), é também especialista em Direito Público pela Escola Paulista de Direito (EPD) e graduado em Direito pela Universidade de São Paulo (USP). Atua como professor de Direito, em regime de dedicação exclusiva, do Curso Clio (Curso Preparatório para o Concurso de Admissão à Carreira Diplomática) e do Curso Damásio.

2 Para ilustrar a magnitude dos impactos que a afirmação do Direito Internacional causou, ao longo do século XX, no campo do Direito Constitucional, interessa citar as considerações de Ferreira Filho (2003, p. 21-22), que registra a existência de teses favoráveis à adoção das normas internacionais de direitos humanos como fatores limitativos da atuação do poder estatal, a exemplo do que ocorreu no processo de construção de novos Estados balcânicos, onde a Comunidade Europeia impôs a adoção de alguns princípios, como o da democracia pluralista e o do respeito aos direitos humanos fundamentais para orientar a auto-organização daqueles entidades soberanas. Em abono a esse ponto de vista, Canotilho (2003, p. 1369 passim) desenvolveu a teoria denominada de "Constitucionalismo Global", cujos pontos nucleares militam em favor da admissão das

Revista da Faculdade Mineira de Direito, v.12, n. 23, jan./jun. 2009 - ISSN 1808-9429. 
constatação é dimensionada a patamares elevados diante de teorias como a do Estado Constitucional Cooperativo, desenvolvida por Peter Häberle. Essa concepção retrata um dos processos de transformação mais significativos vivenciados pelo Estado contemporâneo e pode sinteticamente definida como:

\section{[...] o Estado que justamente encontra a sua identidade também no Direito Internacional, no entrelaçamento das relações internacionais e supranacionais, na percepção da cooperação e da responsabilidade internacional, assim como no campo da solidariedade (HÄBERLE, 2007, p. 4).}

A apregoada abertura do Direito Interno das entidades soberanas para as normas que integram o sistema jurídico do Direito Internacional, indubitavelmente, repercute em vários segmentos de estudo do constitucionalismo e, por óbvio, demonstra sensíveis reflexos na disciplina das práticas do controle de constitucionalidade empreendidas pelos diversos países. Daí o porquê a apreciação das influências que o diálogo permanente travado entre as fontes normativas estatais e as fontes criadoras de normas no Direito das Gentes é tido, na atualidade, como matéria que desperta interesse em toda a comunidade jurídica.

Há de se creditar à observância das convenções e dos demais acordos internacionais surgidos nesse contexto o mérito pela coexistência e cooperação entre nações soberanas, cujos interesses nem sempre são coincidentes. Com efeito, os atuais contornos adquiridos pela relação existente entre Direito Interno e Direito Internacional denotam que a preocupação em assegurar o integral cumprimento das prescrições enunciadas por tratados firmados e devidamente ratificados "incumbe a todos os órgãos do Estado, porque a obrigação de executar impõe-se ao Estado tomado no seu conjunto como sujeito de direito internacional" (DINH, DAILLIER e PELLET, 2003, p. 233). Esse dado - muito relevante para assegurar a observância das normas internacionais no contexto interno dos Estados - poderia, de acordo com uma rápida e infundada conclusão, ser compreendido como obstáculo intransponível para o acionamento dos mecanismos da jurisdição constitucional em relação aos atos normativos contrários à Lei Maior oriundos do Direito Internacional ${ }^{3}$.

Assim é que este trabalho apresenta como proposta analisar, em linhas gerais, as mais proeminentes questões jurídicas derivadas da problemática relativa ao controle de constitucionalidade jurisdicional-repressivo dos tratados internacionais no âmbito do ordenamento pátrio. Trata-se de um tema que há tempos suscita efusivos debates, haja vista que seu enfrentamento exige a abordagem concomitante de aspectos pertencentes ao domínio

normas peremptórias ou imperativas de Direito Internacional (jus cogens) como necessários limites materiais ao exercício do poder constituinte originário dos Estados nacionais.

Revista da Faculdade Mineira de Direito, v.12, n. 23, jan./jun. 2009 - ISSN 1808-9429. 
do Direito Internacional (a relação existente entre normas internas e normas internacionais) e a apreciação de pontos ligados ao Direito Constitucional (estruturação e funcionamento do complexo sistema brasileiro de controle de constitucionalidade).

Não é sem razão, portanto, a anotação de Soares (2002, p. 225) no sentido de que o pano de fundo que serve de suporte a esse estudo "tem dado causa a um verdadeiro caos na doutrina dos internacionalistas brasileiros, que não se entendem entre si, em especial no que se refere ao monismo e ao dualismo, nem com alguns constitucionalistas, aferrados a um nacionalismo de certa forma ultrapassado, ou em descompasso com os fenômenos da globalização a que o País, quer queiram, quer não, se encontra submetido”.

\section{A AFIRMAÇÃO DO PRIMADO DA CONSTITUIÇÃO COMO REQUISITO IMPRESCINDÍVEL PARA A REALIZAÇÃO DO CONTROLE DE CONSTITUCIONALIDADE EM RELAÇÃO AOS ATOS NORMATIVOS INTERNACIONAIS}

A inegável e cada vez mais acentuada permeabilidade dos ordenamentos jurídicos nacionais diante dos atos normativos criados pelos entendimentos entre Estados é comprovada com base na aplicação pelas autoridades pátrias - em geral, juízes e tribunais - dos comandos veiculados em tratados internacionais. Decorre diretamente dessa constatação o amplo interesse do Direito Constitucional sobre o assunto, pois, tal qual registra Almeida (2003, p. 50), "a forma de recepcionar-se o tratado no ordenamento jurídico interno (seja por incorporação automática, seja por incorporação intermediada) não é determinada pelas normas internacionais e sim por decisão do próprio Estado signatário”. Constitui, de tal sorte, matéria reservada à Constituição definir, caso necessário, não apenas o procedimento de internalização das normas convencionais, mas principalmente a posição hierárquiconormativa que deverá ser atribuída ao texto do tratado integrado ao ordenamento nacional de cada Estado.

Em relação à incorporação das convenções internacionais pelos sistemas jurídicos internos, as técnicas empregadas nas Constituições revelarão se o constituinte admite que o Direito Internacional e o Direito Interno "são dois ordenamentos independentes, estanques, ou dois ramos do mesmo sistema jurídico" (HILDEBRANDO, SILVA e CASELLA, 2009, p. 211). A necessidade ou não de um procedimento constitucionalmente disciplinado para a transformação das normas internacionais em normas jurídicas estatais importará, em verdade, na verificação do fato de estar o Estado filiado a uma das correntes doutrinárias que se

3 Cf. Barzelatto (2007, p. 472-473).

Revista da Faculdade Mineira de Direito, v.12, n. 23, jan./jun. 2009 - ISSN 1808-9429. 
convencionou denominar de monismo e de dualismo. Por certo, a compreensão da forma de articulação dos sistemas jurídicos intraestatais e do internacional é essencial para a investigação dos fundamentos que sustentam a afirmação do princípio da supremacia da Constituição diante, inclusive, do Direito Internacional.

Observa-se que o conhecimento dos aportes teóricos ligados a essas duas correntes não deve servir apenas para efeitos de classificação dos Estados como pertencentes a um ou outro grupo. Ao contrário, é importante buscar diretamente nos fundamentos do monismo e do dualismo os instrumentos para que se entenda o sempre complicado "modo de se conceber, genericamente, o Direito Internacional Público e o direito estatal, tomando um em referência ao outro" (RAMOS, 2009, p. 149). Dessa forma, mostra-se oportuno apresentar, mesmo que sucintamente, as principais características que orientam ambas as teorias de interação entre os sistemas jurídicos estatal e internacional.

A primeira vertente, capitaneada pelos teóricos atrelados ao monismo, preconiza a plena integração entre as ordens jurídicas interna e internacional - o que, por conseguinte, implica considerar a norma doméstica e internacional como pertencentes a um único ordenamento. Já a concepção dualista encontra seu principal lastro na ideia de que Direito Interno e Direito das Gentes representam, cada qual, um conjunto de normas independentes e absolutamente distintas. Por esse motivo, torna-se possível definir que a ideia centra desta concepção reflete a necessidade de proceder-se à admissão formal dos tratados ao universo normativo nacional ${ }^{4}$.

Muito mais do que demarcarem um campo específico acerca da recepção de convenções internacionais, ambas as teorias devem também ser analisadas sob o influxo das soluções que proporcionam para eventuais antinomias entre normas internas e normas internacionais no momento de sua aplicação pelo juiz nacional. Nesse particular, verifica-se que o monismo admite duas soluções possíveis para o aludido conflito de comandos normativos: pode permitir a prevalência do direito do Estado (monismo nacionalista ou moderado) ou a primazia da norma internacional (monismo internacionalista ou radical), a depender do que estiver consignado na Constituição de cada organização estatal. O mesmo não se observa em relação ao dualismo, pois, em matéria de harmonização das duas ordens jurídicas, tal concepção parte sempre "do princípio de que um tribunal nacional aplicaria o Direito interno", conforme observa Brownlie (1997, p. 44).

4 Sobre a delimitação conceitual do monismo e dualismo, consultar Mello (1997, p. 103 passim); Dallari (2003, p.7 passim); Cunha e Pereira (p. 89 passim); e Cassese (2005, p. 213 passim).

Revista da Faculdade Mineira de Direito, v.12, n. 23, jan./jun. 2009 - ISSN 1808-9429. 
Registrados os aspectos genéricos ligados às variações do monismo e do dualismo, cabe analisar qual é a amplitude de tais teorias no sistema jurídico brasileiro, tendo como foco os reflexos que podem trazer à operacionalização do controle de constitucionalidade no Direito pátrio. Assim, cabe analisar o princípio da supremacia da Constituição como limite à criação dos atos normativos convencionais que veiculam preceitos de cooperação entre Estados $^{5}$. Interessa esclarecer também as possíveis consequências jurídicas que podem ser sentidas no ordenamento nacional a partir da declaração de inconstitucionalidade dos tratados que não guardem adequação material e formal com os dispositivos constitucionais.

Com base nessas considerações, é preciso ter em mente que, a respeito da relação entre Direito Interno e Direito Internacional, o Brasil filia-se à corrente dualista - o que, consequentemente, indica a indeclinabilidade de observarem-se estritamente as prescrições constitucionais para que haja a perfeita incorporação dos tratados firmados pelo Brasil à ordem interna. Ademais, no tocante aos conflitos normativos entre o Direito Constitucional e as normas internacionais introduzidas, a jurisprudência brasileira pacificou o entendimento de que a solução dessa antinomia ocorre pela prevalência das normas constitucionais ${ }^{6}$. A conclusão segura que se chega é a de que, ao menos neste último aspecto, a Corte Constitucional brasileira demonstra estar em consonância com a orientação estabelecida pela maioria dos Estados contemporâneos ${ }^{7}$.

\section{INTEGRAÇÃO INTERNACIONAL E PRESERVAÇÃO DA SOBERANIA DOS ESTADOS}

Ganha evidência, nesse contexto, o fato de a maior parte dos Estados, mesmo a par da impostergável necessidade de inserção na sociedade internacional e da tomada de consciência de que a cooperação interestatal deve servir de molde para a reformulação estrutural de uma série de fatores, continuar a buscar em suas Constituições as regras elementares para a

5 Reforça-se, aqui, a lição de Kelsen (2007, p. 240) no sentido de que "a função política da Constituição é estabelecer limites jurídicos ao exercício do poder. Garantia da Constituição significa a segurança de que tais limites não serão ultrapassados".

6 A propósito, há paradigmático julgado no STF, relatado pelo Ministro Celso de Mello, em que restou pacificado o entendimento que segue: "Supremacia da CF sobre todos os tratados internacionais. O exercício do 'treaty-making power', pelo Estado brasileiro, está sujeito à observância das limitações jurídicas emergentes do texto constitucional. Os tratados celebrados pelo Brasil estão subordinados à autoridade normativa da CF. Nenhum valor jurídico terá o tratado internacional, que, incorporado ao sistema de direito positivo interno, transgredir, formal ou materialmente, o texto da Carta Política. Precedentes" (STF, MI 772 AgR, Ementa, Rel. Min. Celso de Mello, julgamento em 24/10/2007, Plenário, DJE de 20/03/2009).

7 Almeida (2003, p. 51) atesta esse dado relevante para a operacionalização do controle de constitucionalidade das normas internacionais incorporadas aos ordenamentos nacionais ao afirmar que, "como regra, quase absoluta, tem prevalecido nos diversos Estados o primado da Constituição sobre o direito internacional positivo". Compartilham do mesmo entendimento Bastos e Martins (1995, p. 98), porém, gifram que há países - como a França, a Grécia e o Peru - que consagram o primado do tratado sobre o Direito Interno.

Revista da Faculdade Mineira de Direito, v.12, n. 23, jan./jun. 2009 - ISSN 1808-9429. 
organização das instituições políticas, bem como para guiar a válida e efetiva criação do Direito.

A tradução dessa constatação nos universos da Teoria do Estado e do Direito Constitucional certifica que a soberania permanece, ainda hoje, como atributo conceitual habilitado a descrever as entidades estatais modernas. Nem o surgimento de blocos regionais entre os Estados, nem a consolidação de uma gama de organizações supranacionais, são consideradas suficientemente fortes para fazer ruir a expressividade do princípio do primado da Constituição sobre todos os demais atos normativos integrados ao ordenamento interno (Ramos, 2010, p. 33).

Exemplo mais bem sucedido de integração regional, a União Europeia assiste, conforme retrata Morais (2006, p. 488 passim), à formação de uma notável tensão doutrinária entre "jus-constitucionalistas" e "jus-comunitaristas" sobre a alegada posição supraconstitucional do denominado Direito Comunitário (regulamentos comunitários, diretivas regulamentares "self executing" e decisões supranacionais de conteúdo normativo). Em defesa da primazia das normas constitucionais, Canotilho (2003, p. 826) esclarece que os argumentos levantados pelos defensores da supremacia do Direito Comunitário são insustentáveis diante da verificação de que o conflito entre normas supranacionais e disposições encartadas nas Constituições dos Estados-membros resolve-se pelo critério "de aplicação preferente mas não de preeminência quanto à validade". Na prática, os preceitos constitucionais internos incompatíveis com as normas comunitárias não são nulos ou anuláveis, apenas são inaplicáveis no caso concreto; a resposta para tal espécie de antinomia não passa, portanto, pela manipulação dos métodos inerentes ao controle de constitucionalidade ${ }^{8}$.

Além disso, enfatiza Canotilho que as normas criadas pelos órgãos da União Europeia jamais poderão desencadear processos que subvertam os princípios constitucionais propagados pelos Estados que integram esse bloco regional, sobretudo as disposições constitucionais que se apresentam como materialmente irreversíveis no âmago das Constituições estatais (2003, p. 826-827). Confirma essa diretriz o texto do recente Tratado de Lisboa, cuja vigência se iniciou em 01 dezembro de 2009, e o conteúdo, ao redefinir as

8 Em igual direção, anota Favoreu (1993, p. 61-62) que a contraposição entre ordem jurídica internacional e ordem jurídica nacional, quando analisada sob o ponto de vista do Direito Interno, indica posição hierárquica de destaque em favor do Direito Constitucional, conforme pode ser aferido com base em dois dados: primeiro, os procedimentos de revisão constitucional ainda são regidos pelas Constituições estatais (e não pelos padrões do Direito Internacional, incluído o Direito Comunitário); segundo, persiste o monopólio da jurisdição constitucional atribuído às Cortes dos Estados soberanos, não obstante a sensível influência que a

Revista da Faculdade Mineira de Direito, v.12, n. 23, jan./jun. 2009 - ISSN 1808-9429. 
instituições comunitárias da União Europeia, fez constar expressamente o dever de respeitarse a igualdade e a respectiva identidade nacional dos Estados-membros, identidade essa refletida nas estruturas políticas e constitucionais fundamentais consignadas na Lei Fundamental de cada um dos Estados da Europa (art. $1^{\circ}, 5$, do Tratado de Lisboa, que alterou o art. $3^{\circ}$ do Tratado de Maastricht).

Com efeito, após apreciar as implicações constitucionais do processo de integração europeu, Ramos (2010, p. 36) estatui com segurança que:

[...] no âmbito dos Estados europeus e nos demais Estados soberanos, continua plenamente válida a premissa do constitucionalismo de feições nacionais, determinante de que o direito internacional, seja ele de que natureza for, somente penetra no ordenamento jurídico interno nos termos e condições estabelecidas pela Constituição dotada de supremacia formal. E não interfere na conclusão supra o fato de o princípio da primazia do direito comunitário vir expressamente reconhecido no próprio tratado constitutivo da Comunidade, contando, destarte, com o assentimento dos Estados signatários.

Se mesmo no terreno da experiência internacional mais avançada de integração regional - a União Europeia - ainda persiste incólume o princípio do primado da Constituição diante dos atos normativos internacionais, menor esforço é demandado para esquadrinhar essa problemática no contexto do Brasil e das instituições do Mercosul. A situação brasileira é resumida por Ocampo (2009, p. 89) nos seguintes termos:

\begin{abstract}
[...] diante da ausência de normas que outorgue preeminência aos tratados sobre as leis, a jurisprudência do Supremo Tribunal Federal se orientou para a doutrina de que uma lei ordinária nacional posterior a um tratado pode modificar as convenções deste último, sem prejuízo de que nesses casos o Estado brasileiro deverá assumir a responsabilidade que lhe cabe no campo internacional".
\end{abstract}

E prossegue o autor, advertindo que, "se o constituinte brasileiro não quis dar primazia automática ao tratado em quaisquer circunstâncias, independentemente da cronologia, os juízes não estão autorizados a inventar essa regra somente porque a doutrina o deseja" (Ibid., p. 89).

A inserção do Brasil no Mercosul denota, ao menos no que tange à estatura das normas internacionais na ordem jurídica pátria, o nítido caráter intergovernamental do processo de integração econômica do bloco regional sul-americano, na medida em que inexistem, por ora, órgãos supranacionais habilitados a impor normas e decisões comunitárias ao Estado brasileiro. Ademais, a regra geral de equiparação dos tratados internacionais às leis ordinárias, sedimentada em reiteradas decisões do Supremo Tribunal Federal, impede

jurisprudência das Cortes Comunitárias vem exercendo na interpretação das disposições constitucionais dos Estados que participam do bloco europeu.

Revista da Faculdade Mineira de Direito, v.12, n. 23, jan./jun. 2009 - ISSN 1808-9429. 
terminantemente que se reconheça posição de destaque às normas de integração regional em face dos mandamentos consagrados em nosso texto constitucional ${ }^{9}$.

E, a par de tais dados, arremata Ferreira Filho (2003, p. 26) que "a hipótese de evolução do Mercosul, de que faz parte o Brasil, no sentido de ser esta semelhante à ocorrida na Europa, não pode realizar-se sem alterações no quadro constitucional"10.

Com base no esquadrinhado e ao se voltar as atenções ao objetivo primeiro deste artigo - qual seja, o estudo da atual configuração do sistema nacional de controle de constitucionalidade e a aptidão dos mecanismos existentes para aferir a adequação dos tratados internacionais diante do postulado do primado da Constituição -, pode-se adiantar que, no país, não existe nenhuma convenção internacional imune ao controle de constitucionalidade. A justificativa dessa afirmação encontra arrimo na definição do status normativo que pode ser atribuído aos tratados internacionais de que o Brasil é parte e cujos conteúdos são passíveis de aplicação no território nacional, porque convertidos em normas internas. De fato, é a precisa definição dos possíveis níveis hierárquicos dos tratados no Direito brasileiro que assegura a autoridade da Constituição ante a essas espécies normativas.

\section{A DEFINIÇÃO DAS POSSÍVEIS ESTATURAS HIERÁRQUICO-NORMATIVAS DOS TRATADOS INTERNACIONAIS NO ORDENAMENTO JURÍDICO NACIONAL: PARIDADE EM RELAÇÃO À LEI ORDINÁRIA FEDERAL, SUPRALEGALIDADE E EQUIVALÊNCIA DE EMENDA CONSTITUCIONAL}

A questão do nível hierárquico-normativo assegurado às convenções internacionais no sistema jurídico brasileiro é tratada por Almeida (2003, p. 53), autora que sublinha que a atual Constituição (a exemplo dos textos constitucionais anteriores) não traz disposição expressa estabelecendo privilégios hierárquicos aos tratados. Em virtude do reiterado silêncio de

9 As Constituições do Paraguai e da Argentina divergem dessa orientação, pois seus textos respectivos apresentam indubitável previsão sobre o reconhecimento de uma ordem jurídica supranacional superior inclusive às normas constitucionais de cada um desses Estados. Nesse sentido, proclama o art. $9^{\circ}$ da Carta Constitucional Paraguaia, de 20/06/1992: “A República do Paraguai, em condições de igualdade com outros Estados, admite uma ordem jurídica supranacional que garanta a vigência dos direitos humanos, da paz, da justiça, da cooperação e do desenvolvimento político, econômico, social e cultural"; e o art. 75, inciso 24 da Constituição da Argentina: "Corresponde ao Congresso, aprovar tratados de integração que deleguem competências e jurisdição a organizações supraestatais em condições de reciprocidade e igualdade, e que respeitem a ordem democrática e os direitos humanos. As normas ditadas em sua consequência têm hierarquia superior às leis".

10 Ferreira Filho (2003, p. 26-28) apresenta cinco frentes de alteração constitucional na Lei Maior brasileira para que seja possível atribuir primazia ao Direito Comunitário, a saber: harmonização entre os princípios fundamentais do Direito Comunitário e as regras constitucionais nacionais; admissão expressa da prevalência do Direito Comunitário sobre o direito comum do país; criação de um Tribunal Comunitário para decidir conflitos ligados à interpretação e ao alcance do Direito Comunitário; alteração no sistema constitucional de repartição de competências a fim de delimitar o campo normativo do ente supranacional; e unificação ou harmonização do elenco de direitos fundamentais a serem respeitados pelas diferentes esferas de poder, com a condição de que os litígios a esse respeito sejam submetidos à Corte comunitária.

Revista da Faculdade Mineira de Direito, v.12, n. 23, jan./jun. 2009 - ISSN 1808-9429. 
nossos constituintes, formaram-se diferentes correntes de interpretação na doutrina e na jurisprudência nacionais acerca do status dos acordos internacionais, havendo, até mesmo, defensores do primado dos tratados diante da Constituição ${ }^{11}$.

Não obstante as divergências existentes, o Supremo Tribunal Federal pacificou no ano de 1977, com o julgamento do Recurso Extraordinário no 80.004-SE, relatado pelo Ministro Xavier de Albuquerque, a tese de que, ante a realidade do conflito entre tratado e lei posterior, esta, porque expressão última da vontade do legislador republicano, deve ter sua prevalência garantida pela Justiça - mesmo se isso, no plano internacional, implicar variadas consequências do descumprimento do tratado (REZEK, 2008, p. 99).

Foi o precedente citado que proporcionou a consolidação do entendimento de que os tratados internacionais encontram-se equiparados juridicamente à lei ordinária federal. Embora essa posição tenha resolvido internamente grande parte dos pontos de tensão surgidos da antinomia entre normas internacionais e normas domésticas - pois se concluiu pela aplicação do critério cronológico (norma posterior revoga norma anterior com ela incompatível) como recurso de solução do conflito entre atos legais -, essa orientação recebeu críticas contundentes, sobretudo no tocante à proteção dos direitos humanos estatuídos em tratados internacionais.

A notável intensificação da interação e da conjugação do Direito Internacional e do Direito Interno fortaleceu a sistemática de proteção dos direitos da pessoa humana e, como consequência, determinou a reformulação do tratamento dispensado aos tratados internacionais de direitos humanos no Brasil, mediante o processo de "internalização do Direito Constitucional somado ao processo de constitucionalização do Direito Internacional”, conforme descreve Piovesan (2009, p. 145).

Cabe, aqui, estabelecer a situação particular que os tratados e as convenções que disciplinem matérias afeitas ao universo dos direitos humanos apresentam no atual contexto constitucional pátrio. Em verdade, as normas convencionais sobre direitos humanos, após atendidas todas as etapas necessárias para a incorporação ao sistema normativo pátrio, não mais podem ser equiparadas às leis ordinárias, por força da inovação advinda do processo de reforma constitucional materializado na promulgação, em 2004, da Emenda Constitucional $n^{\circ}$

11 Soares (2002, p. 225) observa que, a despeito do entendimento jurisprudencial hoje assente no sentido de que a aplicação dos tratados internacionais no Brasil deve se alinhar aos comandos do dualismo, essa matéria ainda é responsável por desencontros em sede doutrinária, uma vez que, "no relativo às relações entre o direito interno e o Direito Internacional, [...] desde a primeira Constituição do país, a Constituição do Império do Brasil de 1824, e todas as Constituições republicanas, de 1891, 1934,1937, 1946, 1967, Emenda Constitucional de 1969, inclusive a atual Constituição de 1988, silenciam a respeito do posicionamento 
45, que incluiu o $\S 3^{\circ}$ ao art. $5^{\circ}$ da Lei Maior ${ }^{12}$ e franqueou a possibilidade de conceder-se equivalência de emenda constitucional a tais tratados.

A respeito do papel assumido pela Emenda Constitucional $\mathrm{n}^{\circ}$ 45, Mendes (In: MENDES, COELHO e BRANCO, 2009, p. 742-743) sublinha que o ato reformador conseguiu pacificar a acalorada discussão doutrinária no país sobre o status normativo dos tratados de direitos humanos, na medida em que afastou a tese de que todas as normas convencionais que versassem sobre a proteção do homem seriam dotadas de aplicabilidade imediata e de natureza constitucional.

Também merece ser considerada a importância assumida pela jurisprudência do Supremo Tribunal Federal (STF) na ocasião do julgamento do Recurso Extraordinário n ${ }^{\circ}$ 466.343-SP, em matéria de afirmação da posição hierárquica das convenções internacionais de direitos humanos. O precedente apontado definiu o caráter supralegal dos tratados de direitos humanos que não foram referendados pelo Congresso Nacional nos termos do art. $5^{\circ}$, $\S 3^{\circ}$, da Constituição da República, o que, na prática, acenou para a insuficiência da submissão de tais convenções à tese da equiparação à lei ordinária. A supralegalidade dos tratados de direitos humanos comprova o reconhecimento de que essas convenções, embora não possam afrontar a supremacia da Constituição, têm lugar especial reservado no ordenamento jurídico (Ibid., p. 750).

O breve escorço apresentado autoriza a conclusão de que não há no país nenhum tratado internacional que escape da jurisdição constitucional, seja na modalidade difusa, seja na via concentrada. Como pontuado, a recente jurisprudência do Supremo Tribunal Federal assentou o entendimento de que três são as categorias hierárquicas nas quais os tratados internacionais devidamente internalizados podem ser enquadrados, a saber:

i) paridade normativa em relação às leis ordinárias (convenções que versem sobre matérias estranhas ao campo dos direitos humanos);

ii) supralegalidade (tratados que disciplinem matéria atinente aos direitos humanos, mas que não foram aprovados pelo Congresso Nacional em conformidade com o previsto no art. $5^{\circ}, \S 3^{\circ}$, da Lei Maior); ou;

iii) equivalência de emendas constitucionais (convenções sobre direitos humanos referendadas pelo Congresso Nacional nos termos do art. $5^{\circ}$, § $3^{\circ}$, da Constituição).

hierárquico entre, de um lado, as normas internas, constitucionais e infraconstitucionais, e, de outro, o costume internacional e, sobremaneira, os tratados e convenções internacionais".

12 "Art. $5^{\circ}[\ldots] \S 3^{\circ}$ Os tratados e convenções internacionais sobre direitos humanos que forem aprovados, em cada Casa do Congresso Nacional, em dois turnos, por três quintos dos votos dos respectivos membros, serão equivalentes às emendas constitucionais".

Revista da Faculdade Mineira de Direito, v.12, n. 23, jan./jun. 2009 - ISSN 1808-9429. 
E, sem dúvida, todos os status normativos referidos não isentam os atos internacionais convencionais transpostos para o ordenamento brasileiro do dever de guardar estrita obediência aos comandos constitucionais, sob pena de serem considerados desprovidos de existência e validade jurídica. A propósito, a problemática da submissão das convenções internacionais à autoridade normativa da Constituição é bem sistematizada por Barroso (2009, p. 33-34):

\footnotetext{
Em síntese apertada de tudo que se vem de expor, é possível assentar que, no conflito de fontes interna e internacional, o estágio atual do direito brasileiro, consoante a jurisprudência constitucional e a melhor doutrina, é no sentido de que: a) os tratados internacionais, em geral, são incorporados ao direito interno em nível de igualdade com a legislação ordinária. Inexistindo entre o tratado e a lei relação de hierarquia, sujeitam-se eles à regra geral de que a norma posterior prevalece sobre a anterior. A derrogação do tratado pela lei não eventual responsabilidade internacional do Estado, se este não se valer do meio institucional próprio de extinção de um tratado, que é a denúncia.

b) o tratado celebrado na vigência de uma Constituição e que seja com ela incompatível, do ponto de vista formal (extrínseco) ou material (intrínseco), é inválido e sujeita-se à declaração de inconstitucionalidade incidenter tantum, por qualquer órgão judicial competente, sendo tal decisão passível de revisão pelo Supremo Tribunal Federal, em sede de recurso extraordinário. O tratado que se encontrar em vigor quando do advento de um novo texto constitucional, seja este fruto do poder constituinte originário ou derivado, será tido como ineficaz, se for com ele incompatível.
}

Frente as duas grandes linhas de mudança sentidas pela ordem jurídica pátria em decorrência de influências vertidas do Direito Internacional - o processo de integração econômica do Mercosul e o reconhecimento de estatura diferenciada aos tratados internacionais de direitos humanos nos quais o Brasil seja parte -, mostra-se encorajador verificar em qual intensidade o Brasil demonstra características suficientes para sua inclusão, ainda que parcial, no conceito delineado por Peter Häberle de Estado Constitucional Cooperativo. Para tanto, passa-se, a seguir, à investigação dos impactos que o contínuo desenvolvimento das relações internacionais tem causado à jurisdição constitucional brasileira, em especial no que diz respeito à declaração de inconstitucionalidade de tratados internacionais convertidos em normas nacionais.

\section{A INFLUÊNCIA DA TEORIA DO ESTADO CONSTITUCIONAL COOPERATIVO NOS ASPECTOS TEÓRICOS E PRÁTICOS QUE NORTEIAM O CONTROLE DE CONSTITUCIONALIDADE JURISDICIONAL-REPRESSIVO NO DIREITO BRASILEIRO}

A permanente aproximação dos Estados no cenário internacional, para além da criação de normas internacionais sempre mais específicas e habilitadas a disciplinar as relações interestatais, tem determinado, no âmbito do Direito Interno, que os Estados Constitucionais 
da atualidade atuem como protagonistas do processo de surgimento do denominado Direito comum ou Direito de cooperação. Esse termo, cunhado pela doutrina, manifesta-se, numa perspectiva geral, como "expressão, pressuposto e consequência da cooperação entre Estados" (HÄBERLE, 2007, 63).

Tal Direito comum, indispensável à cooperação entre Estados, concretiza-se, de acordo com as impressões apresentadas por Häberle, mediante normas, processos, competências, objetivos e conteúdos típicos do Direito Internacional, mas que já se adensaram consideravelmente no seio das Constituições nacionais. A construção dessa mencionada categoria de normas jurídicas depende, em larga medida, da atuação da jurisdição constitucional desempenhada pelos Estados em sintonia com os vetores informativos do processo de integração entre Direito Internacional e Direito Interno, consubstanciado na verificação de "unidade da comunidade de Direito Internacional" (Ibidem, p. 64-65).

A teoria do Estado Constitucional Cooperativo carece de estudos no que se refere a sua viabilidade jurídico-constitucional e aplicabilidade concreta, haja vista que seu idealizador adverte categoricamente que esse modelo de Estado contemporâneo "ainda não é um objetivo alcançado, ele se encontra 'a caminho'” (Ibidem, p. 70). E, dentre as várias implicações que tendem a surgir com base na concretização dessa projeção teórica, está a definitiva superação da clássica dicotomia entre dualismo e monismo. Também se acredita que haverá o abandono da concepção de Direito Internacional como instrumento de coexistência entre Estados soberanos, porque o Direito comum revelar-se-á como o Direito de cooperação em uma comunidade internacional na qual a pessoa humana ocupará o ponto central de toda a atuação estatal (Ibidem, p. 70-71) ${ }^{13}$.

Em complemento, Mendes (In: MENDES, COELHO e BRANCO, 2009, p. 746) aduz que, não obstante a complexidade de motivos que conduzem à configuração do caráter cooperativo do Estado Constitucional, os fatores sociológico-econômico e ideal-moral constituem os mais evidentes sinais de que os Estados Nacionais estão adotando essa roupagem institucional.

13 Nesse ponto, é válido informar que Häberle (2007, p. 70-71) resume as características do Estado Constitucional Cooperativo em três frentes, são elas: “Abertura para as relações internacionais com efeito de impor medidas eficientes no âmbito interno (permeabilidade), também no acento da abertura global dos direitos humanos (não mais cerrados no domínio reservado) e de sua realização 'cooperativa'; Potencial constitucional ativo, voltado ao objetivo (e elementos isolados nivelados) de realização internacional 'conjunta' das tarefas como sendo da comunidade dos Estados, de forma processual e material; Solidariedade estatal de prestação, disposição de cooperação para além das fronteiras: assistência ao desenvolvimento, proteção ao meio ambiente, combate aos terroristas, fomento à cooperação internacional também a nível jurídico privado (Cruz Vermelha, Anistia Internacional)",

Revista da Faculdade Mineira de Direito, v.12, n. 23, jan./jun. 2009 - ISSN 1808-9429. 
No que respeita ao aspecto sociológico-econômico, o Estado Constitucional Cooperativo aproxima-se consideravelmente da experiência de integração europeia, especialmente porque vários Estados foram obrigados a alterar suas respectivas Constituições para tornar possível a execução direta de decisões supranacionais criadas pelas autoridades comunitárias. Já, em relação ao fundamento ideal-moral:

\footnotetext{
“[...] não se pode deixar de considerar a proteção aos direitos humanos como a forma mais concreta de que dispõe o sistema constitucional, a exigir dos atores da vida sociopolítica do Estado uma contribuição positiva para a máxima eficácia das normas das Constituições modernas que protegem a cooperação internacional amistosa como princípio vetor das relações entre Estados" (Ibidem, p. 746).
}

A concepção teórica desenvolvida por Häberle sugere, por certo, que as transformações no Direito Internacional dependem invariavelmente de mudanças operadas antes nos Estados Constitucionais. Por isso é que a análise, sob os influxos da proposição teórica do Estado Constitucional Cooperativo, acerca do controle de constitucionalidade dos tratados internacionais desperta notável interesse na doutrina internacional e constitucional. Ademais, na Constituição brasileira vigente pode-se salientar, aprioristicamente, dois pontos que parecem confirmar as ideias propagadas pela teoria do Estado Constitucional Cooperativo: os princípios que regem as relações internacionais da República Federativa do Brasil (art. $4^{\circ}$ ) e a viabilidade de inclusão de tratados internacionais de direitos humanos no bloco de constitucionalidade (art. $\left.5^{\circ}, \S 3^{\circ}\right)$.

Sobre a influência dos princípios disciplinadores das relações internacionais, insculpidos no art. $4^{\circ}$ da Lei Maior, é recomendável a apreciação dos sentidos conferidos pela jurisprudência do Supremo Tribunal Federal aos vetores arrolados nos dez incisos do dispositivo constitucional apontado. A atuação da jurisprudência nacional na delimitação da extensão e da profundidade das referidas normas constitucionais é muito relevante, já que, consoante observam Bastos e Martins, "nosso direito anterior era silente sobre a exata inserção do Brasil no contexto do direito internacional” (1995, p. 450). Poucas são, portanto, as contribuições doutrinárias que informam o conteúdo desses comandos principiológicos imprescindíveis para a concretização da cooperação internacional realizada pelo Estado brasileiro.

Embora sejam poucas as apreciações analíticas empreendidas pelos estudiosos a respeito das influências e mudanças que os princípios constitucionais que orientam as relações internacionais da República Federativa do Brasil, Dallari (2002, p. 21) destaca-se ao consignar que: 
[...] não se pode ignorar a relevância das normas constitucionais que explicitamente tratam das relações exteriores de um país. De um lado, porque, ao fixarem competências para distintos organismos, poderes e esferas do Estado, podem contribuir, considerando-se a evolução de sistemas cada vez mais complexos de gestão pública, para uma reversão da percepção desfocada dos paradigmas das relações internacionais de um país, que os retrata enquanto decorrência automática da política externa governamental, pois instituições não necessariamente vinculadas a esta última, como o parlamento, passam a ter maiores atribuições em torno das questões internacionais. De outro lado, porque ao fixarem princípios, as normas constitucionais estabelecem a primazia dos valores que não deixam de permear não só a retórica, mas a própria materialização dos atos decorrentes da política externa.

A outra linha de abordagem da Constituição Federal sob o prisma do Estado Constitucional Cooperativo refere-se à consequência derivada do status constitucional atribuído aos tratados sobre direitos humanos, que venham a ser incorporados com a observância das exigências do $\S 3^{\circ}$, do art. $5^{\circ}$, da $\mathrm{CF} / 88$. Tais atos convencionais, por apresentarem a possibilidade de equivalerem às emendas constitucionais, assumem a condição de parâmetro para aferição da validade jurídico-constitucional das normas hierarquicamente subalternas14. Desse modo, pontuando a relevância que essa verificação possui para o Direito Constitucional brasileiro, esclarece Ramos (2009, p. 178):

[...] a ideia de bloco de constitucionalidade, largamente utilizada no Direito Constitucional francês desde a década de 1970, passa a se revelar útil entre nós, pois, doravante, as normas dotadas de constitucionalidade formal, isto é, contempladas com organicidade e supremacia hierárquica, compreenderão as normas do corpo permanente da $\mathrm{CF} / 88$ e do Ato das Disposições Constitucionais Transitórias (ADCT), as normas das emendas constitucionais não inseridas na $\mathrm{CF} / 88$ ou no ADCT e, finalmente, as normas dos tratados internacionais de direitos humanos incorporados ao direito nacional nos termos do $\S 3^{\circ}$, do art. $5^{\circ}$, da $\mathrm{CF} / 88$.

O abrigo dos tratados de direitos humanos com equivalência de emendas constitucionais é também apreciado por Monteiro (2011, p. 160-161), com foco na organicidade da Constituição, que conclui:

É a própria Constituição de 1988 , em seu art. $5^{\circ}$, § $3^{\circ}$, que atribui aos tratados internacionais de direitos humanos, aprovados pelo procedimento nele previsto, posição hierárquica constitucional. Assim como a Constituição francesa de 1958, a Constituição de 1946, a Declaração dos Direitos do Homem e do Cidadão de 1789 e os princípios fundamentais reconhecidos pelas leis da República formam o bloco de constitucionalidade francês, sem quebra da organicidade do texto constitucional,

14 Expõe Barroso (2009, p. 36-37) que a equiparação de emenda constitucional admitida para os tratados de direitos humanos aprovados pelo procedimento de votação análogo ao exigido para criação de emendas constitucional "não se trata da criação de uma nova espécie normativa, em acréscimo às do art. 59 da Constituição, mas de atribuição de eficácia qualificada, que dará ensejo à produção de três efeitos diferenciados: a) em caso de conflito entre lei e tratados de direitos humanos, aprovado em conformidade com o art. $5^{\circ}, \S 3^{\circ}$, da $\mathrm{CF}$, prevalecer-se-á o tratado em razão de sua equivalência com as emendas constitucionais (e independentemente do critério cronológico); b) os tratados de direitos humanos incorporados com o art. $5^{\circ}, \S$ $3^{\circ}$, da CF podem servir de parâmetro para o controle de constitucionalidade das leis e dos atos normativos, ampliando o chamado "bloco de constitucionalidade"; c) tais tratados não podem ser objeto de denúncia do Presidente da República, por força do art. $60, \S 4^{\circ}$, da CF.

Revista da Faculdade Mineira de Direito, v.12, n. 23, jan./jun. 2009 - ISSN 1808-9429. 
pois chega-se ao conteúdo desse bloco partindo-se de referência do próprio texto constitucional de 1958, os tratados internacionais de direitos humanos, aprovados pelo procedimento previsto no art. $5^{\circ}, \S 3^{\circ}$, da Constituição da República Federativa do Brasil de 1988, compõem o bloco de constitucionalidade brasileiro, sem quebra da organicidade do texto constitucional, pois chega-se ao conteúdo desse bloco igualmente partindo-se de referência do próprio constitucional de 1988.

Nesse contexto, para perquirir os eventuais reflexos que a cooperação entre Estados fez sentir-se no constitucionalismo pátrio, o sistema brasileiro de controle de constitucionalidade será tomado como centro de atenção, notadamente no que respeita à adoção de tratados internacionais incorporados ao ordenamento pátrio ora como objeto, ora como parâmetro da jurisdição constitucional.

Em verdade, desde já, é importante apresentar um esclarecimento acerca da apreciação, pelo Judiciário brasileiro, da constitucionalidade de atos convencionais internacionais: a declaração de inconstitucionalidade não implicará a nulidade dos tratados, uma vez que não pode a decisão judicial interna atingir atos integrantes do sistema normativo internacional. A declaração de inconstitucionalidade alcança unicamente as normas nacionais responsáveis pela introdução das convenções internacionais em nosso ordenamento, ou seja, o decreto legislativo de aprovação emitido pelo Congresso Nacional e decreto de execução editado pelo Presidente da República (MENDES, 1990, p. 266).

O juízo de contrariedade constitucional que recai diretamente sobre os ditos atos normativos internos responsáveis pela recepção dos tratados na ordem jurídica nacional leva, por certo, a não-aplicação das convenções e dos acordos que estiverem em descompasso com o texto constitucional do Estado. A decretação, pelas autoridades pátrias, de nulidade dos acordos internacionais não faz essas convenções, consideradas em sua natureza e estrutura próprias, serem admitidas como juridicamente inexistentes e inválidas, motivo pelo qual o Estado signatário continuará internacionalmente vinculado ao tratado no plano internacional. Clève (1995, p. 142) confirma esse entendimento ao registrar que:

\footnotetext{
“[...] não há dúvida, todavia, que decretada a inconstitucionalidade de um tratado (rectius, dos atos de aprovação, ratificação e promulgação), a sua não aplicação no direito interno pode implicar a responsabilidade internacional do país. Caberá, neste caso, à União denunciá-lo, sujeitando-se eventualmente às sanções impostas pelo direito internacional".
}

Como se pode depreender, no caso de declaração de inconstitucionalidade dos atos internacionais, a denúncia das convenções que ofenderem a supremacia da Constituição transmuta-se em instrumento complementar da jurisdição constitucional. Talvez o efeito jurídico mais interessante derivado da denúncia seja isentar o Estado denunciante da imputação de responsabilidade por qualquer atuação desconforme à convenção internacional 
rechaçada expressamente pelas autoridades jurisdicionais internas. E é em virtude disso que a denúncia do tratado, em regra, acompanhará a declaração de inconstitucionalidade da convenção feita pelo Judiciário doméstico (Pontes de Miranda, 1970, p. 109).

Desse modo, a denúncia de acordos internacionais em relação aos quais o Brasil esteja vinculado também precisa ser apreciada à luz dos conceitos imanentes à teoria do Estado Constitucional Cooperativo. Isso requer releituras constitucionalmente adequadas do procedimento interno para a efetivação das denúncias de tratados, a exemplo da discussão jurídica que circunda o julgamento da ADI nº 1.625-DF no Supremo Tribunal Federal.

A aludida Ação Direta de Inconstitucionalidade, ajuizada pela Confederação Nacional dos Trabalhadores na Agricultura (CONTAG) e pela Central Única dos Trabalhadores (CUT) contra o Decreto 2.100/96, que tornou pública a denúncia, pelo Brasil, da Convenção 158 da OIT, tem como cerne a discussão sobre a possibilidade de o Presidente da República denunciar tratados internacionais sem o consentimento do Congresso Nacional15, assunto nunca antes enfrentado por nossa Corte Constitucional. Embora o Supremo Tribunal Federal não tenha, até o momento, decidido conclusivamente sobre a imprescindibilidade de aquiescência congressual para validar as denúncias a tratados, identificam-se, na doutrina pátria, consistentes posicionamentos em defesa dessa orientação.

A título ilustrativo, interessa mencionar o entendimento exposto por Pontes de Miranda (1970, p. 109), rebatendo posição contrária capitaneada por Bevilácqua, assim expresso:

Pode o Presidente da República, só, denunciar, os tratados, convenções ou acordos que já foram aprovados pelo Poder Legislativo? Respondeu afirmativamente Clóvis Bevilácqua (Jornal do Comércio, 9 de julho de 1926), mas sem razão. Entendia ele que a regra jurídica constitucional não se referiu à denúncia. Não está certo: aprovar tratado, convenção ou acordo, permitindo que o Poder Executivo o denuncie, sem consulta nem aprovação, é subversivo dos princípios constitucionais.

Chama a atenção os termos consignados no voto proferido pelo Ministro Joaquim Barbosa na ocasião em que se manifestou no julgamento da mencionada ADI $n^{0}$ 1.625-DF, porque demonstra singular preocupação em decidir a questão controvertida com fundamento na interpretação sistemática e harmônica da Constituição Federal. Ficou evidenciada no voto a importância de compatibilizar os preceitos relativos à denúncia dos acordos internacionais (previstos no art. 49, inciso I, e art. 84, inciso VIII, ambos da Lei Maior), com a amplitude normativa dos princípios constitucionais consignados no art. $4^{\circ}$ da Constituição, e que devem

15 Cf. Informativos do STF n ${ }^{\circ} 323,421$ e 549, todos disponíveis no sítio eletrônico www.stf.jus.br, acesso em 30/09/2011.

Revista da Faculdade Mineira de Direito, v.12, n. 23, jan./jun. 2009 - ISSN 1808-9429. 
servir como diretrizes para as relações internacionais da República Federativa do Brasil. Com efeito, a argumentação está pautada na premissa de que a atual Carta Magna, ao estabelecer de maneira sistemática, pela primeira vez na história constitucional do Brasil, princípios que regem as relações exteriores (art. $4^{\circ}$ ), teria reforçado o papel do Parlamento em assuntos de política exterior, o que, em aspectos práticos, indica a competência assegurada a todos os Poderes - não apenas do Executivo - para zelar pela observância de tais princípios, bem como fiscalizar a atuação da política externa brasileira16.

$\mathrm{Na}$ verdade, é crível que o fortalecimento da participação do Legislativo nacional no contexto das práticas internacionais de cooperação entre Estados consubstancia-se, juntamente com o exercício consciente do controle de constitucionalidade pelo Poder Judiciário, em importante mecanismo de concretização do Estado Constitucional Cooperativo. Além disso, mais do que permitir o efetivo surgimento do anunciado Direito comum dos Estados (especialmente no que se refere à proteção dos direitos humanos), mediante a junção concordante do Direito Internacional com o Direito Interno, a adoção desse perfil estatal trará novos institutos e formas de operacionalização da jurisdição constitucional, a exemplo do que já aconteceu em alguns países, como o Brasil, com a figura do bloco de constitucionalidade contendo tratados internacionais como parâmetro para esse controle.

Ao que parece, essa nova interpretação dos ordenamentos jurídicos nacionais, baseada grandemente no ininterrupto diálogo entre Direito das Gentes e Direito Interno, tende a permitir que se vislumbre na atuação integrada do Executivo, Legislativo e Judiciário uma forma de permitir a aproximação dos ordenamentos internos dos Estados porque os sistemas constitucionais passarão, aos poucos, a partilhar de valores comuns. Em uma outra leitura possível, o conceito de Estado Constitucional Cooperativo parece indicar a possibilidade de superação daquela clássica ideia, apresentada primorosamente por Medeiros (1995, p. 245), de que o respeito aos valores democráticos exige que as relações internacionais executadas pelo Chefe de Estado sejam referendadas pelo Parlamento, já que tal missão passará a comportar também a atuação do Poder Judiciário.

\section{CONCLUSÃO}

A aproximação da interpretação das normas consignadas no texto constitucional vigente aos vetores indicativos da teoria do Estado Constitucional Cooperativo evidencia a necessidade de abertura da Constituição nacional às normas convencionais cuja gênese está

16 Cf. Informativo do STF no 549, disponível no sítio eletrônico www.stf.jus.br, acesso em 30/09/2011.

Revista da Faculdade Mineira de Direito, v.12, n. 23, jan./jun. 2009 - ISSN 1808-9429. 
atrelada ao Direito Internacional Público. Esse dado repercute na redefinição, no plano interno, das competências estabelecidas aos três Poderes do Estado no que diz respeito à atuação internacional da República Federativa do Brasil, pois atenta para o fato de que não se pode excluir o Poder Judiciário de tal campo. Nesse diapasão, é verificado que os órgãos jurisdicionais encontram justamente no exercício dos mecanismos de controle de constitucionalidade de leis e demais atos normativos o instrumento habilitado a assegurar a plena observância dos comandos constitucionais voltados à disciplina das relações internacionais promovidas pelo Estado.

Com base nessa perspectiva, a reforma constitucional de 2004, que resultou no advento da Emenda Constitucional $n^{\circ} 45$, trouxe a possibilidade de inclusão de convenções internacionais sobre direitos humanos no bloco de constitucionalidade, desde que aprovadas por procedimento exigido para a edição de emendas constitucionais (art. $5^{\circ}, \S 3^{\circ}$, da CF). Essa inovação representou um avanço até então nunca experimentado pelo constitucionalismo brasileiro, na medida em que autorizou a transformação de alguns atos normativos internacionais em paradigma para a realização do controle de constitucionalidade.

Em igual sentido, a adoção da teoria da supralegalidade em benefício dos tratados internacionais sobre direitos do homem confirma a observância, por parte da Corte Constitucional, do princípio insculpido no art. $4^{\circ}$, inciso II, da Constituição Federal de 1988, por meio do qual o país encontra-se obrigado a zelar, em suas relações com os demais Estados, pela prevalência dos direitos humanos. Em verdade, o que fica patente é que os órgãos internos do Judiciário, ao definir posição diferenciada e de privilégio aos tratados de direitos humanos em relação aos atos normativos de estatura legal, evidenciam avanços concretos na proteção dos referidos direitos no país. Também contribuem decisivamente para que todos os órgãos do Estado brasileiro, nas esferas federal, estadual e municipal, cumpram as prescrições agasalhadas em tais tratados.

Ainda que, num primeiro momento, seja perceptível que os progressos aferidos estejam concentrados em uma matéria específica do Direito Internacional, esse dado deve ser compreendido como um forte sinal indicativo de que o nosso Judiciário tem, nos últimos anos, assumido posição destacada ao decidir questões jurídicas ligadas à execução interna de normas internacionais. Algumas dos novos entendimentos significaram inovações jurisprudenciais que obrigaram a Justiça Constitucional brasileira a rever posicionamentos consagrados, a exemplo do que se assistiu com o reconhecimento da supralegalidade acima referida. Esse quadro, de fato, é bastante elucidativo para não se negar o relevante papel que o 
Judiciário detém no aperfeiçoamento de nosso ordenamento jurídico, inclusive no que é atinente aos tratados internacionais.

Nessa direção, em síntese conclusiva, consigna-se que, a despeito de o Supremo Tribunal Federal manter firme a orientação de submissão das normas do Direito das Gentes aos preceitos constitucionais, seus recentes pronunciamentos convergem para assegurar maior proeminência ao exercício da jurisdição constitucional em face dos atos internacionais. Isso não significa o abandono do entendimento de que, no país, os atos normativos editados durante o iter procedimental responsável pela incorporação de tratados internacionais, independentemente da matéria que versarem, são passíveis de controle de constitucionalidade. Ao que tudo indica, esse entendimento não deixará de ser seguido, a menos que o constituinte originário ou derivado reformador assim disponha, haja vista que as normas constitucionais figuram como responsáveis pela validade e existência de todos os atos dotados de normatividade no plano interno.

Não obstante a manutenção do entendimento que garante máxima força normativa à Constituição, a interpretação que tem sido atribuída às normas da Lei Fundamental de 1988 que abordam, direta ou tangencialmente, o desenvolvimento e a manutenção das relações internacionais parece indicar que nossa Corte Constitucional demonstra sensibilidade à importância de vencer a já superada dicotomia Direito Interno versus Direito Internacional.

Mesmo que seja pouco provável que, em breve, o Judiciário brasileiro - juntamente com os demais Poderes do Estado - abrace a missão materializar a proposta do Direito comum antevista por Peter Häberle, em sua teoria do Estado Constitucional Cooperativo, o diálogo entre as normas estatais e as normas derivadas de tratados internacionais tende a ser o principal instrumento para a evolução do sistema jurídico nacional. Essa anunciada simbiose contribuirá de modo ativo para que o Estado brasileiro não somente honre seus compromissos e obrigações oriundos do Direito das Gentes, mas também potencialize a consecução do necessário do progresso jurídico que beneficiará o país e toda a comunidade internacional.

\begin{abstract}
The main subjects of this paper are the analysis and mapping of the influences determined by the theory of the Cooperative Constitutional State, proposed by Peter Häberle, in the field of the judicial review of international treaties incorporated to the national law. Therefore, we propose to verify the intensity and the ways in which the ideas of Häberle - who advocates, in brief, the need of a broad approximation between Constitutional Law and International Law affect the functioning of our complex constitutional law system, focusing especially on the implications arising from the analysis of the compatibility of the international treaties with regard to the Constitution. Finally, we intend to study the case law evolution processed in the
\end{abstract}


scope of our high courts regarding the hierarchic-normative framework conferred to the conventional normative acts, whose genesis lies in the field of Public International Law.

Keywords: Judicial review. International treaties. Cooperative Constitutional State. Treaty hierarchy.

\section{REFERÊNCIAS}

ACCIOLY, Hildebrando; SILVA, G. E. do Nascimento e; e CASELLA, Paulo Borba.

Manual de Direito Internacional Público, 17ª ed.. São Paulo: Saraiva, 2009.

ALMEIDA, Fernanda Dias Menezes de. A Incorporação dos Tratados Internacionais ao Ordenamento Jurídico Brasileiro. Análise do Tema à luz do Direito Constitucional. Revista do Advogado, Ano 23, no 73, p. 48-53, nov. 2003.

BARROSO, Luís Roberto. Interpretação e aplicação da Constituição: fundamentos de uma dogmática constitucional transformadora, $7^{\circ}$ ed. São Paulo: Saraiva, 2009.

BARZELATTO, Ana María García. Informe en Derecho. Control de constitucionalid de los tratados internacionales con especial referencia al control represivo. Estudios Constitucionales, ano 5, n. 1, p. 469-480, 2007.

BASTOS, Celso Ribeiro e MARTINS, Ives Gandra. Comentários à Constituição do Brasil: Promulgada em 5 de Outubro de 1988, vol. 1. São Paulo: Saraiva, 1995.

BROWNLIE, Ian. Princípios de Direito Internacional Público. Lisboa: Fundação Calouste Gulbenkian, 1997.

CANOTILHO, J. J. Gomes. Direito Constitucional e Teoria da Constituição, $7^{\mathrm{a}}$ ed.. Coimbra: Almedina, 2003.

CASSESE, Antonio. International Law, $2^{\mathrm{a}}$ ed.. New York: Oxford, 2005.

CLÈVE, Clèmerson Merlin. A Fiscalização Abstrata de Constitucionalidade no Direito Brasileiro. São Paulo: Revista dos Tribunais, 1995.

CUNHA, Joaquim da Silva e PEREIRA, Maria da Assunção do Vale. Manual de Direito Internacional Público, $2^{\mathrm{a}}$ ed.. Coimbra: Almedina, 2004.

DALLARI, Pedro Bohomoletz de Abreu. Constituição e Relações Externas. São Paulo: Saraiva, 2002.

Constituição e Tratados Internacionais. São Paulo: Saraiva, 2003.

DELMAS-MARTY, Mireille. Por um Direito Comum. São Paulo: Martins Fontes, 2004.

DINH, Nguyen Quoc; DAILLIER, Patrick e PELLET, Alain. Direito Internacional Público, $2^{\mathrm{a}}$ ed.. Lisboa: Fundação Calouste Gulbenkian, 2003. 
FAVOREU, Louis. Le Controle De Constitutionnalite du Traite de Maastricht el le Developpement du "Droit Constitutionnel International". Revenue Generale de Droit International Public, vol. 97, nº 1, p. 39-66, 1993.

FERRAJOLI, Luigi. A Soberania no Mundo Moderno. São Paulo: Martins Fontes, 2007.

FERREIRA FILHO, Manoel Gonçalves. Aspectos do Direito Constitucional Contemporâneo. São Paulo: Saraiva, 2003.

GABSCH, Rodrigo D’Araujo. Aprovação de Tratados Internacionais pelo Brasil: possíveis opções para acelerar o seu processo. Brasília: FUNAG, 2010.

HÄBERLE, Peter. El Estado Constitucional. México: Universidad Nacional Autonóma de México, 2003.

Estado Constitucional Cooperativo. Rio de Janeiro: Renovar, 2007.

KELSEN, Hans. Jurisdição Constitucional. São Paulo: Martins Fontes, 2007.

MEDEIROS, Antônio Paulo Cachapuz de. O Poder de Celebrar Tratados: Competência dos Poderes Constituídos para a Celebração de Tratados, à luz do Direito Internacional, do Direito Comparado e do Direito Constitucional Brasileiro. Porto Alegre: Sergio Antonio Fabris Editor, 1995.

MELLO, Celso D. de Albuquerque. Direito Internacional Público, vol. 1, 11 a ed.. Rio de Janeiro: Renovar, 1997.

MENDES, Gilmar Ferreira; COELHO, Inocêncio Mártires e BRANCO, Paulo Gustavo Gonet. Curso de Direito Constitucional, $4^{\mathrm{a}}$ ed.. São Paulo: Saraiva, 2009.

MENDES, Gilmar Ferreira. Controle de Constitucionalidade: Aspectos Jurídicos e Políticos. São Paulo: Saraiva, 1990.

MIRANDA, Jorge. Direito Constitucional e Direito Internacional. Revista do Advogado, Ano 23, no 73, p. 89-93, nov. 2003.

MORAIS, Carlos Blanco de. Justiça Constitucional - Tomo I: Garantia da Constituição e Controlo da Constitucionalidade, $2^{\mathrm{a}}$ ed.. Coimbra: Coimbra Editora, 2006.

MONTEIRO, Marco Antonio Corrêa. Tratados Internacionais de Direitos Humanos e Direito Interno. São Paulo: Saraiva, 2011.

OCAMPO, Raúl Granillo. Direito Internacional Público da Integração. Rio de Janeiro: Elsevier, 2009.

PIOVESAN, Flávia. Hierarquia dos Tratados Internacionais de Proteção dos Direitos Humanos Jurisprudência do STF. In: In: O STF e o Direito Internacional dos Direitos Humanos, Alberto do Amaral Junior e Liliana Lyra Jubilut (org.). São Paulo: Quartier Latin, p. 123-145, 2009. 
PONTES DE MIRANDA, Francisco Cavalcante. Comentários à Constituição da República dos E. U. do Brasil, Tomo I, Artigos 1-103. Rio de Janeiro: Editora Guanabara, Waissman, Koogan, Ltda., 1936.

Comentários à Constituição de 1967 com a Emenda n 1, de 1969, Tomo I (Arts. 1-7), $2^{\mathrm{a}}$ ed.. São Paulo: Revista dos Tribunais, 1970.

Comentários à Constituição de 1967 com a Emenda nº 1 , de 1969, Tomo III (Arts. 32-117), 2a ed.. São Paulo: Revista dos Tribunais, 1970.

RAMOS, Elival da Silva. Controle de Constitucionalidade no Brasil: Perspectivas de Evolução. São Paulo: Saraiva, 2010.

Os Tratados Internacionais sobre Direitos Humanos no Direito Constitucional Brasileiro Pós-Emenda Constitucional 45/04. In: O STF e o Direito Internacional dos Direitos Humanos, Alberto do Amaral Junior e Liliana Lyra Jubilut (org.). São Paulo: Quartier Latin, p. 146-188, 2009.

REZEK, Francisco. Direito Internacional Público: Curso Elementar, $11^{a}$ ed.. São Paulo: Saraiva, 2008.

SOARES, Guido Fernando Silva. Curso de Direito Internacional Público, vol. 1. São Paulo: Atlas, 2002.

VALADÉS, Diego (org.). Conversas Acadêmicas com Peter Häberle. São Paulo: Saraiva, 2009.

WAMBIER, Teressa Arruda Alvim et al (coord.). A Reforma do Judiciário: Primeiras Reflexões sobre a Emenda Constitucional n. 45/2004. São Paulo: Revista dos Tribunais, 2005. 